\title{
Efficient pig ICSI using Percoll-selected spermatozoa; evidence for the essential role of phospholipase $\mathrm{C}-\zeta$ in ICSI success
}

\author{
Michiko NAKAI ${ }^{1)}$, Shun-ichi SUZUKI ${ }^{1)}$, Junya ITO ${ }^{2)}$, Dai-ichiro FUCHIMOTO'), \\ Shoichiro SEMBON ${ }^{1)}$, Junko NOGUCHI ${ }^{1)}$, Akira ONISHI ${ }^{3)}$, Naomi KASHIWAZAKI ${ }^{2)}$ and \\ Kazuhiro KIKUCHI) \\ 1)Division of Animal Sciences, Institute of Agrobiological Sciences, National Agriculture and Food Research Organization, \\ Ibaraki 305-8602, Japan \\ 2) Laboratory of Animal Reproduction, School of Veterinary Medicine, Azabu University, Kanagawa 252-5201, Japan \\ ${ }^{3)}$ College of Bioresource Sciences, Nihon University, Kanagawa 252-0880, Japan
}

\begin{abstract}
In pigs, the damaged sperm membrane leads to leakage of phospholipase C- $\zeta$ (PLC $\zeta$ ), which has been identified as a sperm factor, and a reduction of oocyte-activating ability. In this study, we investigated whether sperm selected by Percoll gradient centrifugation (Percoll) have sufficient PLC $\zeta$, and whether the efficiency of fertilization and blastocyst formation after intracytoplasmic sperm injection (ICSI) using Percoll-selected sperm can be improved. Percoll-selected sperm (Percoll group) or sperm without Percoll selection (Control group) were used. A proportion of the oocytes injected with control sperm were subjected to electrical stimulation at $1 \mathrm{~h}$ after ICSI (Cont + ES group). It was found that the Percoll group showed a large amount of PLC $\zeta$ in comparison with the Control group. Furthermore, application of Percoll-selected sperm for ICSI increased the efficiency of fertilization and embryo development. Thus, these results indicate the Percoll-selected sperm have sufficient PLC $\zeta$ and high oocyte-activating ability after ICSI in pigs.
\end{abstract}

Key words: Fertilization, Intracytoplasmic sperm injection, Oocyte activation, Pig

(J. Reprod. Dev. 62: 639-643, 2016)

l: mammals, repetitive rise in the intracellular level of free $\mathrm{Ca}^{2+}$, also known as $\mathrm{Ca}^{2+}$ oscillations, are induced by sperm-specific phospholipase $\mathrm{C}-\zeta$ (PLC $\zeta$ ), which has been identified as the most probable candidate sperm factor [1], during fertilization. This triggers a series of oocyte activation events, such as the destruction of cytostatic factor, degradation of maturation promoting factor, resumption of meiosis, extrusion of cortical granules, and transformation of sperm and oocyte nuclei into male and female pronuclei (PNs), respectively, which in turn leads to embryonic development [2].

Unlike the situation in rodents, the efficiency of PN formation after intracytoplasmic sperm injection (ICSI) in pigs is quite low if the ICSI-oocytes do not receive additional artificial stimulation [3, 4]. Therefore, artificial oocyte stimulation, by electrical stimulation [3-6] or calcium ionophore application [6] is considered to be essential for a successful ICSI. We have previously demonstrated that treatments for disrupting sperm membranes before ICSI, such as sonication to isolate the sperm heads from the tails or treatment with detergent and repeated freezing/thawing, led to leakage of PLC $\zeta$ and reduction in oocyte-activating ability in pigs [7]. The membranes of a majority of boar sperm were damaged and the sperm

Received: July 13, 2016

Accepted: September 5, 2016

Published online in J-STAGE: September 30, 2016

(C)2016 by the Society for Reproduction and Development

Correspondence: M Nakai (e-mail: nakai3@affrc.go.jp)

This is an open-access article distributed under the terms of the Creative Commons Attribution Non-Commercial No Derivatives (by-nc-nd) License $<$ http://creativecommons.org/licenses/by-nc-nd/4.0/>. were immobilized after freezing and thawing procedure. However, we used all the freeze-thawed sperm samples for ICSI irrespective of being live or immobilized because it was difficult to select only live sperm with an intact membrane owing to the fact that sperm motility is lost soon after its transfer into the injection medium during ICSI. Given that the oocytes penetrated by sperm undergo PN formation, it would be expected that such sperm, which have a high ability to fertilize, have sufficient PLC $\zeta$. Therefore, we hypothesized that utilization of sperm containing a large amount of PLC $\zeta$ might considerably improve the efficiency of fertilization and embryonic development after ICSI without any artificial stimulation. Superior boar sperm with high motility and penetrability and intact membranes were selected by Percoll gradient centrifugation (Percoll) [8-10]. The cell density of dead sperm decreases because the extracellular fluid enters into the cytoplasm via passive transport [11]. Therefore, Percoll can separate live and dead sperm by the differences in cell densities. When boar sperm harvested after Percoll were examined by immunofluorescence assay, PLC $\zeta$ was observed to be localized in the post-acrosomal and tail regions, as described previously [7] (Fig. 1-a, b). The signals from the acrosomal region are considered non-specific [7]. The proportion of sperm containing PLC $\zeta$ in the Percoll-selected sperm (Percoll group: $74.2 \pm 7.8 \%$ ) was significantly higher than that in the frozen-thawed sperm without Percoll selection (Control group: 45.7 $\pm 5.7 \%$ ) (Fig. 1-c, -d and Fig. 2). Furthermore, a dense band for PLC $\zeta$ in the sperm selected by Percoll was detected in the western blotting assay (Fig. 3). As expected, sperm with intact membranes contain sufficient PLC $\zeta$ because it is membrane damage that causes PLCל loss [7]. 

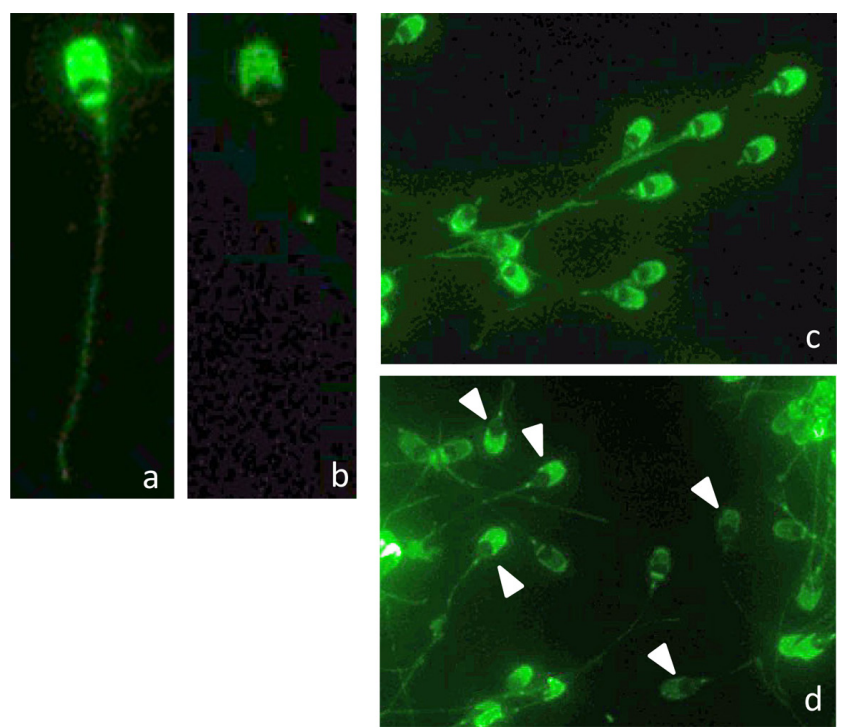

Fig. 1. (a) Labeling of pig sperm with antibody against PLC (green). PLC $\zeta$ is localized in the post-acrosomal tail regions and sperm tails in pig sperm. (b) Sperm, which loses PLC $\zeta$, shows no signal. Arrow heads show sperm with weak- or non-PLC $\zeta$ signal. Immunofluorescence analysis of localization of phospholipase $\mathrm{C}-\zeta$ (PLC $)$ in pig spermatozoa treated with (c) or without (d) Percoll gradient centrifugation.

We evaluated the oocyte-activating ability of Percoll-selected sperm after ICSI (Table 1). The rate of normal fertilization (2 polar bodies and $2 \mathrm{PN}, 2 \mathrm{~PB} 2 \mathrm{PN}$ ) in the Percoll group was significantly higher than that in the Control group $(\mathrm{P}<0.05)$ and equals to that in the electric stimulated oocytes after ICSI (Cont + ES group). In the Control group, more than half of the injected oocytes were arrested at the metaphase-II (M-II) stage but most of the injected sperm nuclei underwent decondensation spontaneously triggered by ooplasmic glutathione [12]. A rise in the intracellular level of free $\mathrm{Ca}^{2+}$ is not necessary for the decondensation [13], whereas transition of the decondensed sperm nucleus to the male PN does require this either [4]. These results suggest that a decrease of oocyte-activating ability of the sperm, possibly attributable to the quantity of PLC $\zeta$ present in the sperm, also leads to failure of male PN formation. However, in cattle, it has been also suggested that no rise in intracellular $\mathrm{Ca}^{2+}$ levels may be caused by the low activity of PLC $\zeta$ or presence of PLC $\zeta$ inside the sperm [14]. Further studies will be needed to clarify the effect of PLC $\zeta$ activity in the injected sperm on induction of oocyte activation after ICSI.

In addition, we investigated the in vitro developmental ability of oocytes injected with Percoll-selected sperm (Table 2). The rate of blastocyst formation in the Percoll and Cont + ES groups was significantly higher than that in the Control group $(\mathrm{P}<0.05)$. In contrast, the mean number of cells per blastocyst, which is an important indicator of embryo quality [13], after electrical stimulation was lower in both, the Percoll and Control groups (Table 2). It has been reported that the pattern of $\mathrm{Ca}^{2+}$ oscillation induced by electrical stimulation differs from that observed in the sperm-penetrated oocytes [15]. It is probable that inappropriate $\mathrm{Ca}^{2+}$ oscillation can

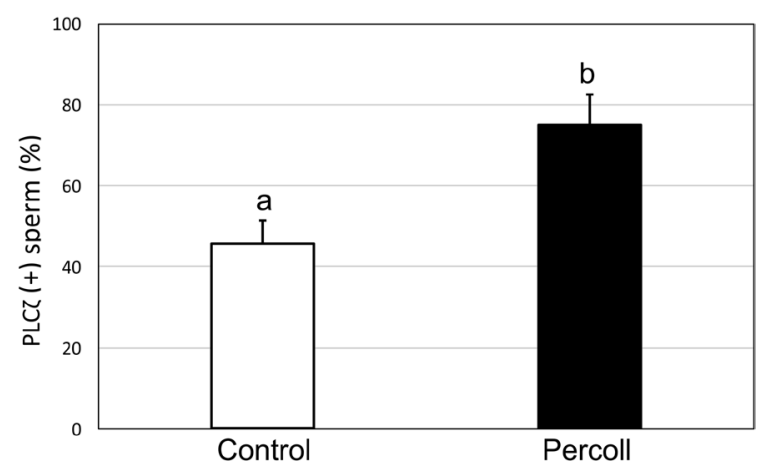

Fig 2. Selection of sperm with phospholipase $\mathrm{C}-\zeta$ (PLC $\zeta$ ) by Percoll gradient centrifugation. Sperm with PLC $\zeta$ signal, as observed via immunofluorescence analysis, were counted. Data are presented as mean \pm SEM for more than three separate experiments. Different superscripts (a $v s . \mathrm{b})$ indicate values that are significantly different $(\mathrm{P}<0.05)$.

act as a signal for induction of apoptosis $[16,17]$. Considering the fact that most blastocysts with low cell numbers are categorized as "partial blastocysts", in which a proportion of blastomeres have died or degenerated, it may be suggested that electrical stimulation was insufficient to induce optimal activation of oocytes injected with sperm in this study. However, the high mean number of cells per blastocyst in the Percoll and Control groups may have been caused by induction of an appropriate $\mathrm{Ca}^{2+}$ oscillation via $\mathrm{PLC} \zeta$ released from the injected sperm.

In conclusion, use of sperm containing an appropriate amount of PLC $\zeta$ for ICSI increases the efficiency of fertilization and embryo development without the need for any artificial stimulation. In addition, physiological oocyte activation via sperm may improve embryo quality.

\section{Materials and Methods}

Protocols for the use of animals were approved by the Animal Care Committee of the Institute of Agrobiological Sciences, National Agriculture and Food Research Organization (NARO), Tsukuba, Japan. All reagents were purchased from Sigma Chemical Company (St. Louis, MO, USA) unless otherwise stated.

\section{Oocyte collection and in vitro maturation}

Ovaries were obtained from pre-pubertal cross-bred gilts (Landrace, Large White, and Duroc breeds) at a local slaughterhouse and transported to the laboratory at $35^{\circ} \mathrm{C}$. Cumulus-oocyte complexes (COCs) were collected from follicles $2-6 \mathrm{~mm}$ in diameter in glucose-free, HEPES-buffered Tyrode medium [18]. In brief, COCs were cultured in six-well dishes (Research Institute for the Functional Peptides, Yamagata, Japan) for 20-22 h in $100 \mu \mathrm{l}$ of maturation medium, a modified North Carolina State University (NCSU)-37 solution [19] containing $10 \%(\mathrm{v} / \mathrm{v})$ porcine follicular fluid, $0.6 \mathrm{mM}$ cysteine, 50 $\mu \mathrm{M} \beta$-mercaptoethanol, $1 \mathrm{mM}$ dibutyl cAMP (dbcAMP), $10 \mathrm{IU} /$ $\mathrm{ml}$ equine chorionic gonadotropin (PMS A for Animal; ZENOAQ, Fukushima, Japan), and $10 \mathrm{IU} / \mathrm{ml}$ human chorionic gonadotropin 

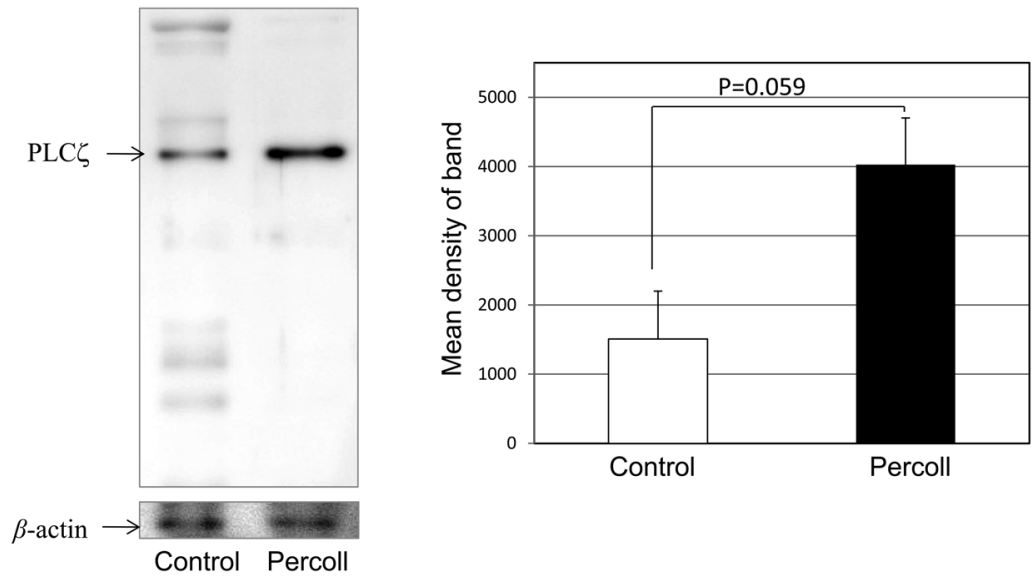

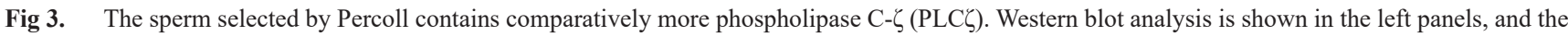
mean values of band intensities are shown in the right panel. Blotting with antibody against $\beta$-actin is also shown as a protein loading control. The concentration of sperm was $5 \times 10^{4}$ cells/lane. Data are presented as mean \pm SEM for three separate experiments.

Table 1. The effects of Percoll-selected sperm derived after gradient centrifugation on oocyte activation

\begin{tabular}{|c|c|c|c|c|c|}
\hline \multirow{2}{*}{ Treatment } & \multirow{2}{*}{ No. of injected oocytes } & \multirow{2}{*}{ M-II (\%) } & \multirow{2}{*}{ Transitional Period (\%) } & \multicolumn{2}{|c|}{ Oocytes with $1 \mathrm{PN}<$} \\
\hline & & & & 2PB2PN (\%) & Others $(\%)$ \\
\hline \multirow[t]{2}{*}{ Control } & 60 & 33 & 6 & 19 & 2 \\
\hline & & $\left(55.0 \pm 6.2^{a}\right)$ & $(10.0 \pm 3.3)$ & $\left(31.7 \pm 3.4^{\mathrm{a}}\right)$ & $\left(3.3 \pm 1.4^{\mathrm{a}}\right)$ \\
\hline \multirow[t]{2}{*}{ Percoll } & 73 & 12 & 10 & 48 & 3 \\
\hline & & $\left(16.4 \pm 5.4^{b}\right)$ & $(13.7 \pm 4.9)$ & $\left(65.8 \pm 3.0^{b}\right)$ & $\left(4.1 \pm 3.0^{\mathrm{a}}\right)$ \\
\hline \multirow[t]{2}{*}{ Cont + ES } & 59 & 2 & 13 & 33 & 11 \\
\hline & & $\left(3.4 \pm 1.7^{b}\right)$ & $(22.0 \pm 7.1)$ & $\left(55.9 \pm 4.4^{b}\right)$ & $\left(18.6 \pm 4.4^{b}\right)$ \\
\hline
\end{tabular}

The injected sperm is selected with or without Percoll gradient centrifugation (Percoll group and Control group). A part of oocytes injected with control sperm were activated by electrical stimulation (Cont + ES group). At $10 \mathrm{~h}$ after ICSI, oocytes were classified into following four categories: 1) M-II: metaphase-II stage, 2) transitional period: total of anaphase-II, telophase-II, metaphase-III stages, 3) 2PB2PN: oocytes with two polar bodies and two pronuclei, 4) others: more than one pronucleus formation except 2PB2PN. Different superscripts $(a, b)$ within same column indicate values that are significantly different $(\mathrm{P}<0.05)$. Data are presented as mean $\pm \mathrm{SE}$ of more than three separate experiments.

Table 2. The effects of Percoll-selected sperm derived after gradient centrifugation on in vitro embryonic development

\begin{tabular}{lccc}
\hline \multicolumn{1}{c}{ Treatment } & No. of injected oocytes & Blastocyst formation $(\%)$ & Mean No. of cells per blastocyst \\
\hline Control & 41 & 8 & $53.5 \pm 14.6^{\mathrm{ab}}$ \\
& 47 & $\left(19.5 \pm 4.1^{\mathrm{a}}\right)$ & $52.2^{\mathrm{a}} \pm 5.2^{\mathrm{a}}$ \\
Percoll & 44 & 17 & $31.1^{\mathrm{a}} \pm 3.9^{\mathrm{b}}$ \\
Cont + ES & & $\left(36.2 \pm 6.7^{\mathrm{b}}\right)$ & $(6$ \\
\end{tabular}

The injected sperm is selected with or without Percoll gradient centrifugation (Percoll group and Control group). A part of oocytes injected with control sperm were activated by electrical stimulation (Cont + ES group). Different superscripts $(a, b)$ within same column indicate values that are significantly different $(P<0.05)$. Data are presented as mean $\pm \mathrm{SE}$ of more than three separate experiments.

(Puberogen; ZENOAQ). They were subsequently cultured for $24 \mathrm{~h}$ in maturation medium without dbcAMP and hormones. Maturation culture was carried out at $39^{\circ} \mathrm{C}$ in an atmosphere of $\mathrm{CO}_{2}, \mathrm{O}_{2}$, and $\mathrm{N}_{2}$ adjusted to $5 \%, 5 \%$, and $90 \%$, respectively $\left(5 \% \mathrm{CO}_{2}\right.$ and $5 \%$
$\mathrm{O}_{2}$ ). After the maturation culture, cumulus cells were removed from the oocytes by treatment with $150 \mathrm{IU} / \mathrm{ml}$ hyaluronidase and gentle pipetting. Denuded oocytes with a first polar body were harvested under a stereomicroscope and used as in vitro-matured oocytes. 


\section{Preparation of sperm}

Epididymal spermatozoa were collected from a Landrace boar and cryopreserved [20,21]. The spermatozoa were thawed in phosphate-buffered saline (PBS; Nissui Pharmaceutical, Tokyo, Japan) supplemented with $5 \mathrm{mg} / \mathrm{ml}$ bovine serum albumin (BSA; Fraction V) (PBS-BSA), and centrifuged for $2 \mathrm{~min}$ at $700 \times \mathrm{g}$. The sperm pellet was resuspended in PBS-BSA (Control group).

Percoll gradient centrifugation was performed as described by Noguchi et al. [10]. The $50 \%$ and $80 \%(\mathrm{v} / \mathrm{v})$ solution of Percoll (GE Healthcare UK, Buckinghamshire, England) was prepared by adding five-strength modified Modena solution. Thawed semen $(0.5$ $\mathrm{ml}$ ) was mixed with $2 \mathrm{ml}$ of $50 \%$ Percoll and then slowly layered over $2 \mathrm{ml}$ of $80 \%$ Percoll in a $15-\mathrm{ml}$ tube. After centrifugation at 700 $\times g$ for $20 \mathrm{~min}$, the pellet at the bottom of the tube was recovered and washed in PBS-BSA by centrifugation at $700 \times g$ for $2 \mathrm{~min}$ to remove the Percoll (Percoll group). Each batch of treated sperm was maintained at room temperature $\left(25^{\circ} \mathrm{C}\right)$ until use.

\section{Procedure for sperm injection}

Two solutions were prepared for ICSI-1) for oocytes, a modified NCSU-37 solution without glucose but supplemented with $0.17 \mathrm{mM}$ sodium pyruvate, $2.73 \mathrm{mM}$ sodium lactate (Kanto Chemical, Tokyo, Japan), $4 \mathrm{mg} / \mathrm{ml}$ BSA, $50 \mu \mathrm{M} \beta$-mercaptoethanol (IVC-PyrLac) [22], and $20 \mathrm{mM}$ HEPES (Dojindo, Kumamoto, Japan), with the osmolality adjusted to $285 \mathrm{mOsm} / \mathrm{kg}$ (IVC-PyrLac-HEPES) [20]; and 2) for sperm, IVC-PyrLac-HEPES supplemented with 4\% (w/v) polyvinyl pyrrolidone (MW 360,000) (IVC-PyrLac-HEPES-PVP). Spermatozoa were injected as described previously [23]. About 20 oocytes were transferred to a $20-\mu l$ drop of IVC-PyrLac-HEPES. The solution containing the mature oocytes was placed on the cover of a plastic dish (Falcon 35-1005; Thermo Fisher Scientific, Waltham, MA, USA). A small volume $(0.5 \mu \mathrm{l})$ of the sperm suspension was transferred to a $2-\mu 1$ drop of IVC-PyrLac-HEPES-PVP, which was prepared close to the drops used for the oocytes. All drops were covered with paraffin oil (Paraffin Liquid; Nacalai Tesque, Kyoto, Japan). The spermatozoa were subjected with a piezo-pulse on their neck region and then injected into the ooplasm using a piezo-actuated micromanipulator (PMAS-CT150; Prime Tech, Ibaraki, Japan). The sperm-injected oocytes were then cultured in IVC-PyrLac at $38.5^{\circ} \mathrm{C}$ under $5 \% \mathrm{CO}_{2}$ and $5 \% \mathrm{O}_{2}$.

\section{Electrical stimulation (ES)}

One $\mathrm{h}$ after the injection, several oocytes injected with control sperm were transferred to stimulation solution consisting of $0.28 \mathrm{M}$ $d$-mannitol, $0.05 \mathrm{mM} \mathrm{CaCl}_{2}$ (Katayama Chemical, Osaka, Japan), 0.1 $\mathrm{mM} \mathrm{MgSO}_{4}$, and $0.1 \mathrm{mg} / \mathrm{ml} \mathrm{BSA}$ and washed three times. They were then stimulated with a direct current pulse of $1.5 \mathrm{kV} / \mathrm{cm}$ for $20 \mu \mathrm{sec}$, using a somatic hybridizer (SSH-2 Shimadzu, Kyoto, Japan). After stimulation, the oocytes were washed and cultured in IVC-PyrLac.

\section{In vitro culture (IVC)}

Two types of IVC medium were prepared [22]. The first was IVC-PyrLac and the second contained $5.55 \mathrm{mM}$ glucose (Wako Pure Chemical Industries, Osaka, Japan), as used in the originally reported NCSU-37 medium, and was supplemented with $4 \mathrm{mg} / \mathrm{ml}$ BSA and $50 \mathrm{mM} \beta$-mercaptoethanol (IVC-Glu). For the first two days, IVC-PyrLac was used. The medium was changed once, to IVC-Glu, on the second day of IVC, and this medium was used for subsequent culture for four days. The IVC was carried out at $38.5^{\circ} \mathrm{C}$ under $5 \% \mathrm{CO}_{2}$ and $5 \% \mathrm{O}_{2}$.

\section{Assessment of fertilization and embryonic development}

The sperm-injected oocytes and cultured embryos were mounted on glass slides and fixed in $25 \%(\mathrm{v} / \mathrm{v})$ acetic acid in ethanol, stained with $1 \%(\mathrm{w} / \mathrm{v})$ orcein in $45 \%(\mathrm{v} / \mathrm{v})$ acetic acid, and observed under a phase-contrast microscope. The proportion of fertilized oocytes was examined at $10 \mathrm{~h}$ after injection. We defined fertilization as the presence of two polar bodies and two PNs (2PB2PN). The rate of blastocyst formation and the mean number of cells per blastocyst were also examined at Day 6 (the day of injection and/or electrical stimulation was defined as Day 0).

\section{Western blotting}

Western blotting was carried out as described previously [24] with some modifications. Porcine PLC $\zeta$ (pPLC $\zeta$ ) was detected using anti-PLC $\zeta$ rabbit serum generated against a $19-$ mer sequence (MENKWFLSMVRDDFKGGKI) at the N-terminus of pPLC $\zeta$ (accession no. BAC78817) [25]. Each sample was mixed with $2 \times$ Laemmli Sample Buffer (Bio Rad, Hercules, CA, USA) and was stored at $-80^{\circ} \mathrm{C}$ until use. After denaturing by boiling at $99.5^{\circ} \mathrm{C}$ for $3 \mathrm{~min}$, samples were separated by SDS-PAGE using $10 \%$ polyacrylamide gel and then transferred to PVDF membranes (Millipore, Darmstadt, Germany). Each membrane was blocked with blocking buffer [5\% (w/v) skimmed milk in PBS] supplemented with $0.1 \%$ Tween 20 (T-PBS), followed by incubation with anti-PLC $\zeta$ antibody (1:5000) overnight at $4^{\circ} \mathrm{C}$ in T-PBS. After three washes in T-PBS, the membranes were treated with horseradish peroxidaselabeled anti-rabbit immunogloblin $\mathrm{G}$ (IgG; 1:5000, Cell Signaling Technology, Danvers, MA, USA) in T-PBS for $1 \mathrm{~h}$ at $4^{\circ} \mathrm{C}$. After one wash at $15 \mathrm{~min}$ and five washes at $5 \mathrm{~min}$ each with T-PBS, peroxidase activity was visualized using the ECL Plus Western blotting detection system (GE Healthcare Japan, Tokyo, Japan), according to the manufacturer's instructions. The intensity of the bands was analyzed using ImageJ software (Ver. 1.41, National Institutes of Health, Bethesda, Maryland, USA).

\section{Immunofluorescence assay}

Immunofluorescence assay was performed as reported previously [26]. Immediately after each treatment, sperm sample was centrifuged $(600 \times g, 2 \mathrm{~min})$ and the pellet was resuspended and incubated with $3.7 \%$ paraformaldehyde in PBS for $30 \mathrm{~min}$ at $4^{\circ} \mathrm{C}$. After centrifugation, the pellet was resuspended in PBS containing $0.1 \%(\mathrm{v} / \mathrm{v})$ Triton X-100 and then incubated for $10 \mathrm{~min}$ at room temperature. The sperm suspension was then spotted as $20-\mu 1$ drops onto glass slides and allowed to attach to the slide for $20 \mathrm{~min}$ at $37^{\circ} \mathrm{C}$. The slides were blocked in $5 \%$ normal goat serum (NGS, Cedarlane Laboratories, Hornby, ON, Canada) in PBS for $3 \mathrm{~h}$ at $4^{\circ} \mathrm{C}$ and then incubated overnight at $4^{\circ} \mathrm{C}$ with anti-pPLC $\zeta(1: 200)$ in $5 \%$ NGS. Washes were performed with T-PBS, followed by $1 \mathrm{~h}$ incubation at room temperature with Alexa Fluor 488-labeled goat anti-rabbit antibody (1:200; Molecular Probes, Eugene, OR, USA) as the secondary antibody. After several washings in T-PBS, the 
presence of PLC $\zeta$ was observed using a standard inverse microscope equipped with appropriate standard fluorescence facilities for green fluorescent protein (GFP) dye at a magnification of $\times 200$. For each group, the fluorescence of three independent samples of more than 100 cells each was evaluated.

\section{Statistical analysis}

Percentage data were subjected to arcsine transformation [27] before statistical analysis. All data were subjected to analysis of variance (ANOVA) and Tukey's multiple range test using the Statcel 2 program (OMS Publishing, Saitama, Japan). Differences were considered significant at $\mathrm{P}<0.05$. All data were expressed as mean \pm SEM, and experiments were repeated more than three times.

\section{Acknowledgments}

We would like to thank Ms Iijima K for technical assistance. This study was supported in part by a Grant-in-Aid for Scientific Research (KAKENHI) from Japan Society for the Promotion of Science (JSPS) to MN (26850172).

\section{References}

1. Saunders CM, Larman MG, Parrington J, Cox LJ, Royse J, Blayney LM, Swann K, Lai FA. PLC $\zeta$ : a sperm-specific trigger of $\mathrm{Ca}^{2+}$ oscillations in eggs and embryo development. Development 2002; 129: 3533-3544. [Medline]

2. Schultz RM, Kopf GS. Molecular basis of mammalian egg activation. Curr Top Dev Biol 1995; 30: 21-62. [Medline] [CrossRef]

3. Lee JW, Tian XC, Yang X. Failure of male pronucleus formation is the major cause of lack of fertilization and embryo development in pig oocytes subjected to intracytoplasmic sperm injection. Biol Reprod 2003; 68: 1341-1347. [Medline] [CrossRef]

4. Nakai M, Kashiwazaki N, Takizawa A, Maedomari N, Ozawa M, Noguchi J, Kaneko H, Shino M, Kikuchi K. Morphologic changes in boar sperm nuclei with reduced disulfide bonds in electrostimulated porcine oocytes. Reproduction 2006; 131: 603-611. [Medline] [CrossRef]

5. Lai L, Sun Q, Wu G, Murphy CN, Kühholzer B, Park KW, Bonk AJ, Day BN, Prather RS. Development of porcine embryos and offspring after intracytoplasmic sperm injection with liposome transfected or non-transfected sperm into in vitro matured oocytes. Zygote 2001; 9: 339-346. [Medline] [CrossRef]

6. Probst S, Rath D. Production of piglets using intracytoplasmic sperm injection (ICSI) with flowcytometrically sorted boar semen and artificially activated oocytes. Theriogenology 2003; 59: 961-973. [Medline] [CrossRef]

7. Nakai M, Ito J, Sato K, Noguchi J, Kaneko H, Kashiwazaki N, Kikuchi K. Pretreatment of sperm reduces success of ICSI in the pig. Reproduction 2011; 142: 285-293. [Medline] [CrossRef]

8. Matás C, Coy P, Romar R, Marco M, Gadea J, Ruiz S. Effect of sperm preparation method on in vitro fertilization in pigs. Reproduction 2003; 125: 133-141. [Medline] [CrossRef]

9. Suzuki K, Nagai T. In vitro fertility and motility characteristics of frozen-thawed boar epididymal spermatozoa separated by Percoll. Theriogenology 2003; 60: 1481-1494.
[Medline] [CrossRef]

10. Noguchi M, Yoshioka K, Hikono H, Iwagami G, Suzuki C, Kikuchi K. Centrifugation on Percoll density gradient enhances motility, membrane integrity and in vitro fertilizing ability of frozen-thawed boar sperm. Zygote 2015; 23: 68-75. [Medline] [CrossRef]

11. Mouri H, Hoshi M. Therapy for male infertility. In: Morisawa M, Hoshi K, Okabe M (eds.), Spermatology New Edition. Tokyo University Press; 2006: 420-421.

12. Perreault SD, Naish SJ, Zirkin BR. The timing of hamster sperm nuclear decondensation and male pronucleus formation is related to sperm nuclear disulfide bond content. Biol Reprod 1987; 36: 239-244. [Medline] [CrossRef]

13. Zijlstra C, Kidson A, Schoevers EJ, Daemen AJJM, Tharasanit T, Kuijk EW, Hazeleger W, Ducro-Steverink DWB, Colenbrander B, Roelen BAJ. Blastocyst morphology, actin cytoskeleton quality and chromosome content are correlated with embryo quality in the pig. Theriogenology 2008; 70: 923-935. [Medline] [CrossRef]

14. Malcuit C, Maserati M, Takahashi Y, Page R, Fissore RA. Intracytoplasmic sperm injection in the bovine induces abnormal $\left[\mathrm{Ca}^{2+}\right]_{\mathrm{i}}$ responses and oocyte activation. Reprod Fertil Dev 2006; 18: 39-51. [Medline] [CrossRef]

15. Sun FZ, Hoyland J, Huang X, Mason W, Moor RM. A comparison of intracellular changes in porcine eggs after fertilization and electroactivation. Development 1992; 115 947-956. [Medline]

16. Gordo AC, Rodrigues P, Kurokawa M, Jellerette T, Exley GE, Warner C, Fissore R. Intracellular calcium oscillations signal apoptosis rather than activation in in vitro aged mouse eggs. Biol Reprod 2002; 66: 1828-1837. [Medline] [CrossRef]

17. Ozil JP, Markoulaki S, Toth S, Matson S, Banrezes B, Knott JG, Schultz RM, Huneau D, Ducibella T. Egg activation events are regulated by the duration of a sustained $\left[\mathrm{Ca}^{2+}\right]$ cyt signal in the mouse. Dev Biol 2005; 282: 39-54. [Medline] [CrossRef]

18. Bavister BD, Leibfried ML, Lieberman G. Development of preimplantation embryos of the golden hamster in a defined culture medium. Biol Reprod 1983; 28: 235-247. [Medline] [CrossRef]

19. Petters RM, Wells KD. Culture of pig embryos. J Reprod Fertil Suppl 1993; 48: 61-73. [Medline]

20. Kikuchi K, Nagai T, Kashiwazaki N, Ikeda H, Noguchi J, Shimada A, Soloy E, Kaneko H. Cryopreservation and ensuing in vitro fertilization ability of boar spermatozoa from epididymides stored at $4^{\circ} \mathrm{C}$. Theriogenology 1998; 50: 615-623. [Medline] [CrossRef]

21. Ikeda H, Kikuchi K, Noguchi J, Takeda H, Shimada A, Mizokami T, Kaneko H. Effect of preincubation of cryopreserved porcine epididymal sperm. Theriogenology 2002 57: 1309-1318. [Medline] [CrossRef]

22. Kikuchi K, Onishi A, Kashiwazaki N, Iwamoto M, Noguchi J, Kaneko H, Akita T, Nagai T. Successful piglet production after transfer of blastocysts produced by a modified in vitro system. Biol Reprod 2002; 66: 1033-1041. [Medline] [CrossRef]

23. Nakai M, Kashiwazaski N, Takizawa A, Hayashi Y, Nakatsukasa E, Fuchimoto D, Noguchi J, Kaneko H, Shino M, Kikuchi K. Viable piglets generated from porcine oocytes matured in vitro and fertilized by intracytoplasmic sperm head injection. Biol Reprod 2003; 68: 1003-1008. [Medline] [CrossRef]

24. Ito J, Yoshida T, Kasai Y, Wakai T, Parys JB, Fissore RA, Kashiwazaki N. Phosphorylation of inositol 1,4,5-triphosphate receptor 1 during in vitro maturation of porcine oocytes. Anim Sci J 2010; 81: 34-41. [Medline] [CrossRef]

25. Kurokawa M, Sato K, Wu H, He C, Malcuit C, Black SJ, Fukami K, Fissore RA. Functional, biochemical, and chromatographic characterization of the complete $\left[\mathrm{Ca}^{2+}\right]$ oscillation-inducing activity of porcine sperm. Dev Biol 2005; 285: 376-392. [Medline] [CrossRef]

26. Seita Y, Ito J, Kashiwazaki N. Removal of acrosomal membrane from sperm head improves development of rat zygotes derived from intracytoplasmic sperm injection. $J$ Reprod Dev 2009; 55: 475-479. [Medline] [CrossRef]

27. Snedecor GW, Cochran WG. Statistical Methods, $8^{\text {th }}$ ed. The Iowa State University Press; 1989: 273-296. 